\title{
An Agent-Based System to Minimize Earthquake-Induced Damages
}

\author{
Yoshiya Takeuchi, Takashi Kokawa, Ryota Sakamoto, \\ Hitoshi Ogawa and Victor V. Kryssanov \\ College of Science and Engineering, Ritsumeikan University \\ Japan
}

\section{Introduction}

Over 2000 earthquakes happen every year in Japan, so that this country is often called earthquake-ridden (Government of Japan, 2006). There exists a serious problem to prevent the occurrence of earthquake-induced disasters, such as fire, short-circuits, gas leakage, etc. With the recent advent of nation-wide telecommunication networks, real-time earthquake information can be received at every household, and it can thus be utilized to control consumer electronics and reduce the risk of these earthquake-provoked disasters (Kueppers, 2002).

Real-time information about the seismic activity in Japan is provided by the national earthquake early warning system operated by the Japan Meteorological Agency, JMA (Doi, 2002). By sensing primary waves, this system can notify people (e.g. via radio and TV channels, a mobile phone subscription service, etc.) several seconds before the earthquake devastating secondary waves hit a specific area.

The Japan Electronics and Information Technology Industries Association (JEITA) has recently introduced an automatic consumer electronics control system (JEITA, 2005). When an earthquake early warning is received, this system provides services, such as activating alarms, stopping gas, opening doors, and the like. This system cannot, however, comply with the specific situation at each particular household, as circumstantial information about who live/stay in, where they are, what they currently do, etc. is not utilized by the system.

In the presented study, we propose an agent-based system for the earthquake-induced disaster prevention. The system uses household-specific knowledge and can provide for generally a higher level of safety for the inhabitants than existing systems with similar goals do. The proposed system realizes a distributed architecture - a design solution making it quite reliable in (post-)earthquake conditions. There are specialized agents installed in different places (e.g. of a house or a public facility) and called "room agents," which are autonomous, monitor various appliances and people in the rooms, and can control the equipment and electronics, and guide evacuation when an earthquake happens. For the control, countermeasure agents processing different types of rules are set up. During an earthquake, a countermeasure agent receives earthquake data and selects appropriate constraints, which are to be used by the room agents. As there can often be conflicts when 
simultaneously applying control rules obtained from different countermeasure agents, the system implements a conflict-resolving mechanism to produce an optimized set of rules by solving a weighted constraint satisfaction problem with achievement parameters.

In the chapter's remainder, the earthquake early warning system is first outlined. The architecture of a system prototype developed by the authors is then presented. Next, it is explained how the developed system agents act. A case study of the control of home appliances is described. The ability of the system to guide evacuation in an earthquake situation is analyzed through several simulation experiments. Finally, related work is briefly discussed, and conclusions are drawn.

\section{The early warning system}

All earthquakes produce two types of shock waves: primary (P) and secondary (S). $\mathrm{P}$-waves arrive first and usually do not cause any damages. S-waves follow P-waves, are much stronger, and often result in devastation and loss of lives. The earthquake early warning system operated by the JMA deals with current seismic information, such as magnitude of an earthquake and place of its occurrence, obtained by sensing and processing data of the P-waves. Since P-waves are propagated about twice as fast as S-waves (excepting for the case of epicentral earthquakes), the system can usually provide earthquake information to its clients seconds to tens of seconds before the damaging wave hits an area.

In the presented study, a program developed by the Japan Weather Association and the Earthquake Research Institute at the University of Tokyo is used to calculate the expected seismic intensity and time of the S-wave arrival at a specific location for a given earthquake, based on the earthquake early warning data (Kikuchi, 2004).

\section{The agent-based system}

\subsection{System architecture}

Fig. 1 shows the architecture of the system proposed in this study. An earthquake information agent (EIA) is a "JAVA wrapping" of the program processing earthquake early warning data. The EIA receives an earthquake early warning from the JMA and calculates the S-wave arrival time and the expected seismic intensity. The EIA then communicates to three countermeasure agents: an earthquake countermeasure agent (ECA), a personal care agent (PCA), and a precondition for consumer electronics control agent (PCCA). The ECA utilizes general rules for earthquake disaster prevention. The PCA applies personalized rules by utilizing inhabitant-related information. The PCCA makes use of appliance-specific rules to appropriately control consumer electronics and other equipment in the room. The countermeasure agents propose constraints to room agents. After a room agent communicates (or attempts to communicate) to the countermeasure agents to update its rules, it generates, through resolving achievement-weighted constraints, a set of instructions to control the appliances and, possibly, to guide the evacuation process.

\subsection{Human status and the system interface}

Fig. 2 shows the experimental environment - a living room - used in the study. The room space is divided into 9 locations and a corridor (location 10) with spotlights to help navigate 


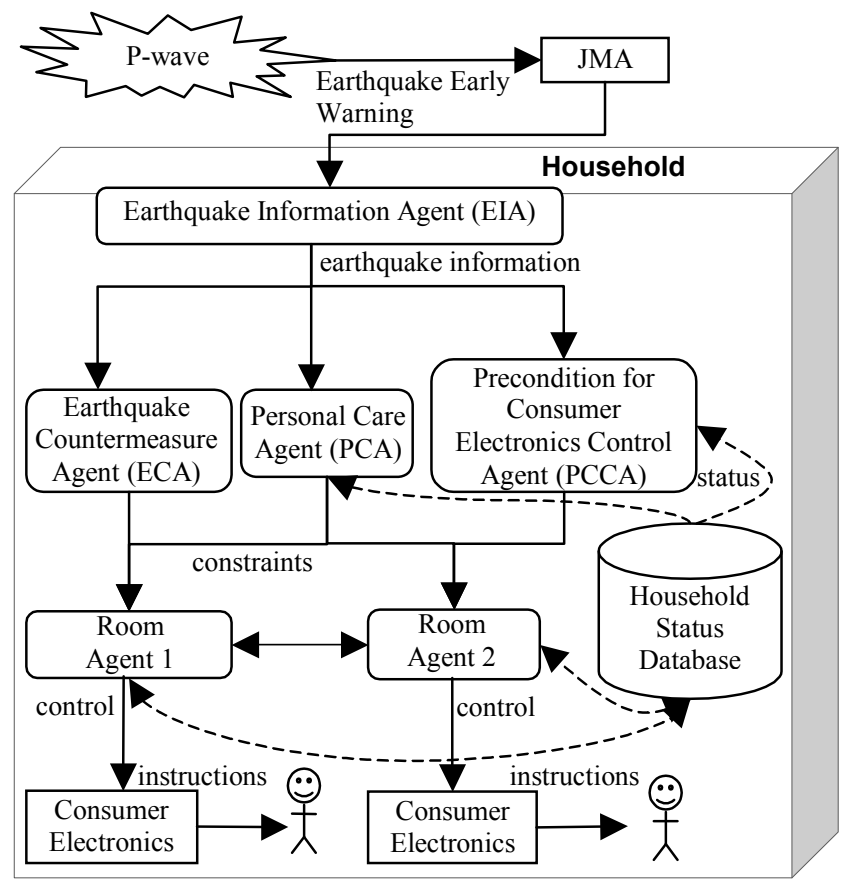

Fig. 1. System architecture

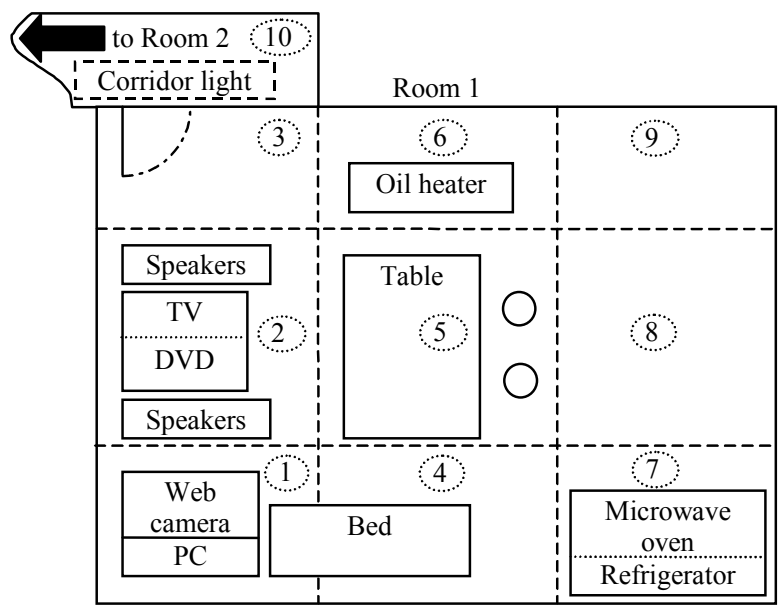

Fig. 2. Experimental environment (Room 1)

people. Current human and consumer electronics statuses are stored in the Household Status Database. Tables 1 and 2 list typical records of the database, which are continuously updated while the room agents monitor the environment. Table 1 gives an example of human statuses. The human status domain is a list of generally expected behavior, which is 
created, based on a personal profile (e.g. a healthy young man is expected to be able to help other people in the house, while someone with a badly injured leg could hardly move without assistance). Actions recommended by the system are selected from the corresponding pre-defined domains. (The difference in the domains shown in Table 1 is due to the difference in the individuals' current statuses.)

There are two types of human statuses processed by the system: static and dynamic. The static status is a general, "permanent" (or rarely changed) description of an individual present in the room: the individual's gender, age, physical abilities, etc. The dynamic status is regularly updated information about the individual's current behavior (e.g. sleeping/resting, being involved in noisy activities, etc.) and location. The dynamic status information is obtained by using RFID tags and an image-recognition system (with a camera connected). For example, when a person registered in the household database (i.e. someone with a static status record) enters the room, her or his location data of the dynamic status is updated, as the person approaches the corresponding sensors of the room agent. Any individual having no static status is automatically associated with a temporary "visitor/guest" profile generated by the system.

A consumer electronics status (Table 2) is predefined at the time when the corresponding appliance is installed. A domain for the control of the electronics and other equipment is also predefined (e.g. by downloading relevant rule-sets via a consumer electronics network), based on the appliance type and manufacturer. The current statuses of the appliances are updated when the electronics are controlled, whether automatically or manually.

When an earthquake early warning is received, room agents resolve achievement-weighted constraints, and a status rule-set for the consumer electronics and people in the room is determined. The system can change the electronics statuses by sending control signals (e.g. via infrared channels). Human behavior cannot, however, be controlled as such, and the system instead issues instructions, based on the most recently registered (static and dynamic) human status. At this point, the current status is (attempted to be) recognized with the sensors, and the records may be updated in the database.

\begin{tabular}{cccc}
\hline $\begin{array}{c}\text { Individual's } \\
\text { ID\# }\end{array}$ & $\begin{array}{c}\text { Current (dynamic) } \\
\text { status }\end{array}$ & $\begin{array}{c}\text { Location } \\
\text { (Room) }\end{array}$ & Domain for the human behavior variables \\
\hline 1 & $\begin{array}{c}\text { Watching (DVD), } \\
\text { low activity }\end{array}$ & 5 & $\begin{array}{c}\text { \{Normal, Sleeping, Watching(X), Hiding } \\
\text { under(X), Staying away from(dangerous } \\
\text { object), Being accompanied, Making a } \\
\text { contact, Reporting own location\} }\end{array}$ \\
2 & $\begin{array}{c}\text { Sleeping, } \\
\text { no activity }\end{array}$ & 1 & $\begin{array}{c}\text { (1) } \\
\text { accomal, Sleeping, Watching(X), Being } \\
\text { Reporting own location\} }\end{array}$ \\
\hline
\end{tabular}

Table 1. Human status

The system keeps continuously updating the status database and producing control and evacuation instructions, based on the latest available information about the dynamically changing environment and the human behavior. The system thus realizes a "latent" interface for consumer electronics and other controlled equipment (e.g. oil or/and gas heaters, doors, etc.) by sensing and processing not only the early warning information received from the EIA, but also the response (of both the inhabitants and the electronics) to the instructions issued by the system, which is registered by the room agents. The interface 
is self-adapting (in the sense that its current state mainly depends on its previous state) and proactive (in the sense that it tries to minimize catastrophic consequences of earthquakeinduced problems, which may arise in the future).

\begin{tabular}{|c|c|c|c|}
\hline $\begin{array}{c}\text { Appliance / } \\
\text { equipment }\end{array}$ & $\begin{array}{l}\text { Current } \\
\text { status }\end{array}$ & Location & Domain of the control variables \\
\hline TV & On(DVD) & 2 & $\{\mathrm{On}(\mathrm{TV}), \mathrm{On}(\mathrm{DVD}), \mathrm{On}(\mathrm{CH}$ num $), \mathrm{Off}\}$ \\
\hline DVD & Play(DVD) & 2 & $\{$ On, Play(DVD), $\operatorname{Rec}(\mathrm{CH}$ num $)$, Off $\}$ \\
\hline Speaker & On(DVD) & 2 & $\begin{array}{c}\text { \{On(TV), On(DVD), On(PC), } \\
\text { Announce }(X), \text { VolUp, VolDown, Off }\}\end{array}$ \\
\hline Light 1 & Off & 1 & $\{$ On, Off $\}$ \\
\hline Light 2 & On & 2 & $\{\mathrm{On}, \mathrm{Off}\}$ \\
\hline Light 3 & Off & 3 & $\{$ On, Off $\}$ \\
\hline Light 4 & Off & 5 & $\{$ On, Off $\}$ \\
\hline Corridor light & Off & 10 & $\{$ On, Off $\}$ \\
\hline Web-camera & Off & 1 & $\{$ Record, On, Off $\}$ \\
\hline Heater & On & 6 & $\{$ On, Off $\}$ \\
\hline Phone & Off & 1 & $\{$ Connect $($ Person $h)$, Off $\}$ \\
\hline Micro-wave oven & Off & 7 & $\{\mathrm{On}, \mathrm{Off}\}$ \\
\hline Refrigerator & On & 7 & $\{\mathrm{On}, \mathrm{Off}\}$ \\
\hline
\end{tabular}

Table 2. Consumer electronics status (Room 1)

\subsection{Constraints for the control}

A room agent determines appropriate (optimized) control instructions by solving an achievement-weighted constraint satisfaction problem, AWCSP (Kokawa \& Ogawa, 2004). An AWCSP solver implemented in the system is an enhanced reasoning engine for constraint satisfaction problems (CSP) that allows for obtaining a Pareto optimal solution even when the invoked constraints are too strict. The AWCSP is similar to the classic CSP (Walliser \& Branschen, 2004) and is represented with a set of variables, a domain of values for each variable, and a set of constraints, but it also requires a set of constraint weights and a set of constraint achievement degrees defined. Various theoretical and applied aspects of AWCSP were actively studied in the past 10 years (Bistarelli et al., 1999; Luo et al., 2002; Schiex et al., 1995), as it became a relatively popular reasoning technique for agent-based systems (Yokoo, 2001).

In the developed system, consumer electronics statuses and human actions are represented as follows: a set of consumer electronics states, $C E=\left\{c e_{1}, c e_{2}, c e_{3}, \ldots, c e_{n}\right\}$, where $n$ is the number of appliances installed; a set of human actions, $A C T=\left\{a c t_{1}, a c t_{2}, \ldots, a c t_{m}\right\}$, where $m$ is the number of the inhabitants. Domains of the variables are represented as $D_{C E}=\left\{d_{c e_{1}}, d_{c e_{2}}\right.$, $\left.\ldots, d_{c e_{n}}\right\}$ and $D_{A C T}=\left\{d_{a c t_{1}}, d_{a c t_{2}}, \ldots, d_{a c t_{m}}\right\}$, respectively.

The ECA handles general countermeasure rules for earthquake disaster prevention, which are usually pre-defined. The PCA deals with human-related rules by utilizing information about the current status of each inhabitant. The PCCA processes specialized rules, based on a control policy defined for the household. The countermeasure agents produce constraints for the variables by utilizing the relevant rules. In a room agent, a set of constraints is represented as $C=\left\{c_{1}, c_{2}, \ldots, c_{k}\right\}, k$ is the number of constraints. Below, these are examples of the knowledge of countermeasure agents: 


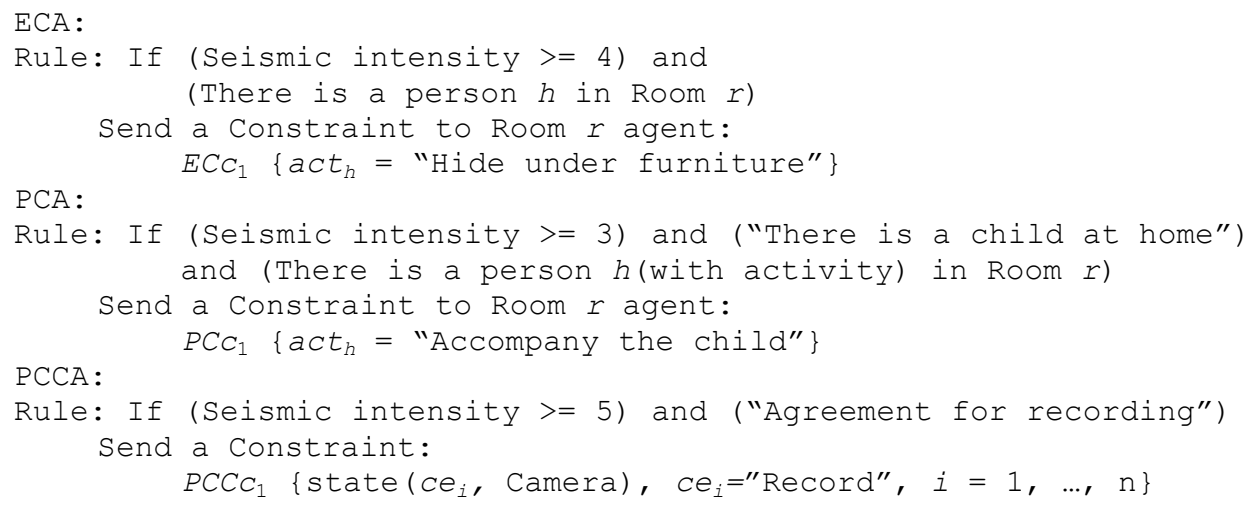

PCA also defines rules to support people with disabilities. For example, for those with hearing disabilities, important information is delivered in a visual form, e.g. on a TV screen or simply with blinking light. Analogously, whenever people with reduced vision are present in the room, all important information is delivered via voice and sound channels.

Constraints generated by the agents may often be in conflict. For example, if there is no furniture to hide under, a constraint "Hide under furniture" would never be satisfied, and no instructions would be issued by the system. The room agent should still recommend an accomplishable action for the inhabitants, such as, for example, "Stay away from dangerous objects." If one then tries to represent the expected behavior with weighted constraints, the rules become complicated and difficult to maintain the integrity (Yokoo, 2001). To cope with this problem, achievement degrees are defined for the constraints. When a constraint is fully satisfied, the room agent chooses a variable value having the highest achievement degree.

An achievement degree is a parameter showing when and to what extent a given constraint is satisfied. This parameter consists of a variable and a threshold. A set of the achievement variables $A=\left\{a_{1}, a_{2}, \ldots, a_{k}\right\}$ represents satisfaction degrees of the constraints. A set of achievement thresholds $F=\left\{f_{1}, f_{2}, \ldots, f_{k}\right\}$ gives thresholds that the values of $a_{i}, i=1, \ldots, k$, must achieve to make the constraints satisfied.

An example of achievement degrees for a constraint, which refers to issuing recommendations that would help maintain a higher safety level for the inhabitants, is given in Table 3.

\begin{tabular}{ccc}
\hline Achievement degree & $\begin{array}{c}\text { Safety } \\
\text { Level }\end{array}$ & Actions \\
\hline$a_{i}=$ (achievable & 5 & Hide under furniture (table, etc.) \\
safety level / & 4 & Stay away from dangerous objects (window, etc.) \\
recommended safety & 3 & Accompany someone \\
level by & 2 & Make a contact (via mobile, etc.) \\
constraint $\left.c_{i}\right) \times 100$ & 1 & Report location \\
& 1 & No action required \\
\hline
\end{tabular}

Table 3. Achievement degrees and recommended actions 
The assignment of values to the variables is done via an optimization procedure. Room agents produce sets of variable values corresponding to achievement degrees higher than the achievement threshold of a constraint. Room agents then calculate $M$, an "optimization degree" of the whole set as the following sum:

$$
M=\sum_{i=1}^{k} \begin{cases}w_{i}, & f_{i}=100, \\ w_{i} \times \frac{a_{i}-f_{i}}{100-f_{i}}, & f_{i}<100 .\end{cases}
$$

If a constraint $c_{i}$ is completely satisfied, the corresponding summand is the constraint's weight $w_{i}$. Otherwise, the added value is a product of the constraint's weight $w_{i}$ and the normalized distance between the achievement degree value $a_{i}$ and the achievement threshold $f_{i} ; k$ is the total number of constraints. Of course, there may be used formulas other than the above to calculate $M$, depending on the optimization strategy chosen (e. g. see Schiex et al., 1995).

\section{Case study}

In this section, we describe a case study of the development of (a prototype of) the system shown in Fig. 1 for the environment specified in Tables 1-2 and (partly) in Fig. 2. Table 4 exemplifies situations considered in the case study, and Table 5 lists constraints and constraint parameters for the situations.

Situation 1 is, perhaps, the most usual (or expected) situation: Person 1 is relaxing in the living room, while a middle-level earthquake occurs; there is enough time for the action stipulated by $c_{2}$.

Situation 2: Person 1 is sleeping, and the system needs to awake her or him as specified with $c_{7}$.

Situation 3: the difference between Situations 3 and 2 is that there is not enough time for action in the former case. The system cannot advise to move to a safer place, as it would very likely cause panic rather than improve the overall safety.

Situations 4 and 5 show possible interactions between Room 1 and Room 2 agents, as assumed with $c_{4}$. There is a conflict between $c_{2}$ and $c_{4}$, since there is no furniture to hide under in Room 2 (this room is not shown in Fig. 2 but is assumed to be a Japanese-style tatami room with no furniture; see Fig. 4.). If Person 1 does not go to Room 2 but, instead, hides under the table, Person 1's own safety is maintained, but the safety of Person 2 with no activity is not. On the other hand, if Person 1 goes to Room 2 and accompanies Person 2, the own safety of Person 1 cannot be maintained sufficiently high, but the safety level of Person 2 is improved. In this experiment, the weights of $c_{2}$ and $c_{4}$ are the same, and the constraint achievement thresholds $f_{2}$ and $f_{4}$ are balanced to help the person with no activity, depending on the seismic intensity and the remaining time. Every household member is assumed to have a mobile phone.

Situation 6: there is a specified rule in the household policy. Constraint $c_{8}$ allows for making a video record for rescue operations or future analysis. Owing to privacy issues, the agreements of this type's constraints depend on the household privacy policy. 


\begin{tabular}{|c|c|c|c|c|c|}
\hline $\begin{array}{c}\text { Situation } \\
\text { number }\end{array}$ & $\begin{array}{l}\text { Person } 1 \\
\text { status (in } \\
\text { Room 1) } \\
\end{array}$ & $\begin{array}{l}\text { Person } 2 \\
\text { status (in } \\
\text { Room 2) } \\
\end{array}$ & $\begin{array}{l}\text { Electronics } \\
\text { Status }\end{array}$ & $\begin{array}{c}\text { Early } \\
\text { warning } \\
\text { information } \\
\end{array}$ & Explanation \\
\hline 1 & $\begin{array}{l}\text { Watching } \\
\text { a movie }\end{array}$ & $\begin{array}{c}- \\
\text { (no data) }\end{array}$ & $\begin{array}{l}\text { TV and DVD } \\
\text { are turned ON }\end{array}$ & $\begin{array}{l}\text { Seismic } \\
\text { intensity is 4; } \\
\text { Remaining } \\
\text { time is 20sec }\end{array}$ & $\begin{array}{l}\text { The system needs to get } \\
\text { attention of Person } 1 \text { for } \\
\text { announcing instructions }\end{array}$ \\
\hline 2 & $\begin{array}{l}\text { Sleeping, } \\
\text { no activity }\end{array}$ & $\begin{array}{c}- \\
\text { (no data) }\end{array}$ & $\begin{array}{l}\text { Refrigerator } \\
\text { and micro- } \\
\text { wave oven are } \\
\text { turned ON } \\
\text { (stand-by) }\end{array}$ & $\begin{array}{l}\text { Seismic } \\
\text { intensity is } 4 ; \\
\text { Remaining } \\
\text { time is } 22 \mathrm{sec}\end{array}$ & $\begin{array}{l}\text { The system needs to wake } \\
\text { Person } 1 \text { up (alarm and } \\
\text { room light ON) }\end{array}$ \\
\hline 3 & $\begin{array}{l}\text { Sleeping, } \\
\text { no activity }\end{array}$ & (no data) & $\begin{array}{l}\text { Refrigerator } \\
\text { and micro- } \\
\text { wave oven are } \\
\text { turned ON } \\
\text { (stand-by) }\end{array}$ & $\begin{array}{c}\text { Seismic } \\
\text { intensity is 5; } \\
\text { Remaining } \\
\text { time is } 4 \mathrm{sec}\end{array}$ & $\begin{array}{c}\text { There is not enough time } \\
\text { to sensibly act (e.g. escape } \\
\text { / hide anywhere) }\end{array}$ \\
\hline 4 & $\begin{array}{l}\text { Reading a } \\
\text { book }\end{array}$ & $\begin{array}{l}\text { Sleeping, } \\
\text { no activity }\end{array}$ & $\begin{array}{l}\text { Room lights } \\
\text { are turned ON }\end{array}$ & $\begin{array}{l}\text { Seismic } \\
\text { intensity is 4; } \\
\text { Remaining } \\
\text { time is } 21 \mathrm{sec}\end{array}$ & $\begin{array}{l}\text { Person } 1 \text { would (attempt } \\
\text { to) help Person } 2 \text { in Room } \\
2\end{array}$ \\
\hline 5 & $\begin{array}{l}\text { Watching } \\
\text { a movie }\end{array}$ & $\begin{array}{l}\text { Sleeping, } \\
\text { no activity }\end{array}$ & $\begin{array}{l}\text { TV and DVD } \\
\text { are turned ON }\end{array}$ & $\begin{array}{l}\text { Seismic } \\
\text { intensity is 5; } \\
\text { Remaining } \\
\text { time is } 10 \text { sec }\end{array}$ & $\begin{array}{l}\text { For Person } 1 \text {, there is not } \\
\text { enough time to run to } \\
\text { Person } 2 \text {; An alternative } \\
\text { way to help Person } 2 \\
\text { needs to be found }\end{array}$ \\
\hline 6 & $\begin{array}{l}\text { Reading a } \\
\text { book }\end{array}$ & (no data) & $\begin{array}{l}\text { Room lights } \\
\text { are turned ON }\end{array}$ & $\begin{array}{c}\text { Seismic } \\
\text { intensity is 7; } \\
\text { Remaining } \\
\text { time is 3sec }\end{array}$ & $\begin{array}{l}\text { If the policy at the } \\
\text { household allows for } \\
\text { using the camera, turn it } \\
\text { on to possibly assist } \\
\text { future rescue operations }\end{array}$ \\
\hline
\end{tabular}

Table 4. Pre-earthquake situations

Table 6 shows results - constraint parameters obtained as well as main actions undertaken of the electronics control by the system. An example of the calculation of achievement degrees in Situation 1 is listed below:

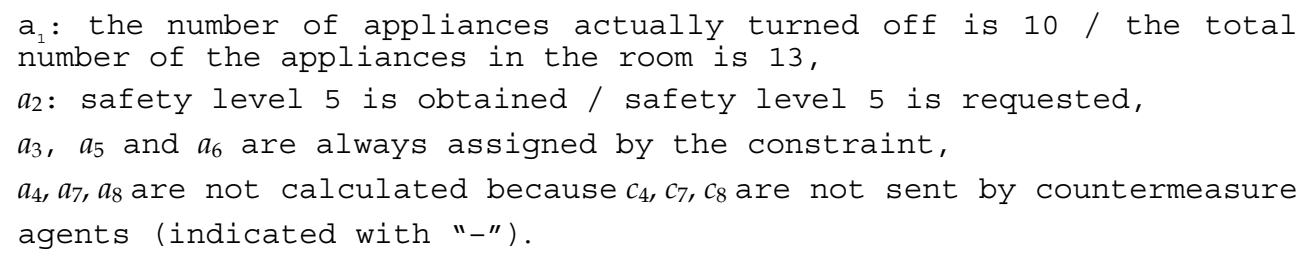

Note that in Situation 5, constraint $c_{4}$ cannot be completely satisfied, since the remaining time is too short (10c). The system then issues an alternative recommendation "Make a 
contact (via a mobile phone)" with a safety level 2 through solving the optimization problem defined with constraints $c_{2}$ and $c_{4}$.

\begin{tabular}{|c|c|c|c|c|c|}
\hline $\begin{array}{l}\text { Constrain } \\
\text { t number }\end{array}$ & $\begin{array}{c}\text { Constraint } \\
\text { specification } \\
(i=1, \ldots, n) \\
\end{array}$ & Agent & $\begin{array}{l}\text { Constra } \\
\text { int } \\
\text { weight }\end{array}$ & $\begin{array}{l}\text { Achievement } \\
\text { degree }\end{array}$ & Explanation \\
\hline$c_{1}$ & $\begin{array}{l}\text { state }\left(c e_{i}, \text { all }\right. \\
\text { electronics }), \\
c e_{i}=\text { "OFF" }\end{array}$ & ECA & 3 & $\begin{array}{c}\text { Electronics } \\
\text { actually turned } \\
\text { off / all } \\
\text { electronics in the } \\
\text { room }\end{array}$ & $\begin{array}{c}\text { Turn off electronics for } \\
\text { preventing electric } \\
\text { shocks }\end{array}$ \\
\hline$c_{2}$ & $\begin{array}{c}a c t_{h}=\text { "Hide under } \\
\text { furniture", } \\
h: \text { adult }\end{array}$ & $\mathrm{ECA}$ & 5 & $\begin{array}{l}\text { Depends on the } \\
\text { human action's } \\
\text { safety level }\end{array}$ & $\begin{array}{l}\text { Act to maintain own } \\
\text { safety }\end{array}$ \\
\hline$C_{3}$ & $\begin{array}{l}\text { state }\left(c e_{i}, \text { Heater }\right), \\
c e_{i}=\text { "OFF" }\end{array}$ & ECA & 6 & $\begin{array}{l}\text { This constraint } \\
\text { must always be } \\
\text { satisfied }\end{array}$ & $\begin{array}{c}\text { Turn off all the } \\
\text { equipment, which may } \\
\text { cause fires }\end{array}$ \\
\hline$c_{4}$ & $\begin{array}{c}a c t_{h}=\text { "Accompany } \\
a ", \\
a: \text { with "no activity", } \\
h: \text { adult }\end{array}$ & PCA & 5 & $\begin{array}{l}\text { Depends on the } \\
\text { human action's } \\
\text { safety level }\end{array}$ & $\begin{array}{l}\text { If there is any "weak" } \\
\text { person (e.g. child), act } \\
\text { to help her or him }\end{array}$ \\
\hline$C_{5}$ & $\begin{array}{l}\text { state }\left(c e_{i} \text { light }\right), c e_{i}= \\
\text { “On", (ce located } \\
\text { near the person) }\end{array}$ & PCA & 4 & $\begin{array}{l}\text { This constraint } \\
\text { must always be } \\
\text { satisfied }\end{array}$ & $\begin{array}{l}\text { To facilitate human } \\
\text { evacuation and record } \\
\text { the person's location } \\
\text { for rescue operations }\end{array}$ \\
\hline $\mathcal{C}_{6}$ & $\begin{array}{c}\text { state( }\left(c e_{i}, \text { Speaker), }\right. \\
\qquad e_{i}= \\
\text { “Announce(earthqu } \\
\text { ake information)” }\end{array}$ & PCA & 4 & $\begin{array}{l}\text { This constraint } \\
\text { must always be } \\
\text { satisfied }\end{array}$ & $\begin{array}{l}\text { Deliver earthquake } \\
\text { information and } \\
\text { navigate the person }\end{array}$ \\
\hline$c_{7}$ & $\begin{array}{c}\text { state }\left(c e_{i}, \text { Speaker }\right), \\
c e_{i}=\text { "VolUp" }\end{array}$ & PCA & 4 & $\begin{array}{l}\text { This constraint } \\
\text { must always be } \\
\text { satisfied }\end{array}$ & $\begin{array}{l}\text { System can do "VolUp" } \\
\text { and "Announce }(X) \text { " at } \\
\text { the same time }\end{array}$ \\
\hline$C_{8}$ & $\begin{array}{l}\text { state }\left(c e_{i}, \text { Camera }\right), \\
c e_{i}=\text { "Record" }\end{array}$ & PCCA & 2 & $\begin{array}{l}\text { Depends on the } \\
\text { household } \\
\text { policy settings }\end{array}$ & $\begin{array}{c}\text { Make a video record for } \\
\text { rescue or future } \\
\text { analysis }\end{array}$ \\
\hline
\end{tabular}

Table 5. Constraint list for Room 1 agent

\section{Simulation experiments}

\subsection{Simulator}

In the previous section, we described constraints utilized to control consumer electronics, as well as instructions apparently suitable to guide the evacuation process. Generally however, there is always a chance that the people (and, to a less extent, the equipment) would not act as expected. Another possible source of complications is the fact that people would almost unavoidably interact with each other when evacuating. 


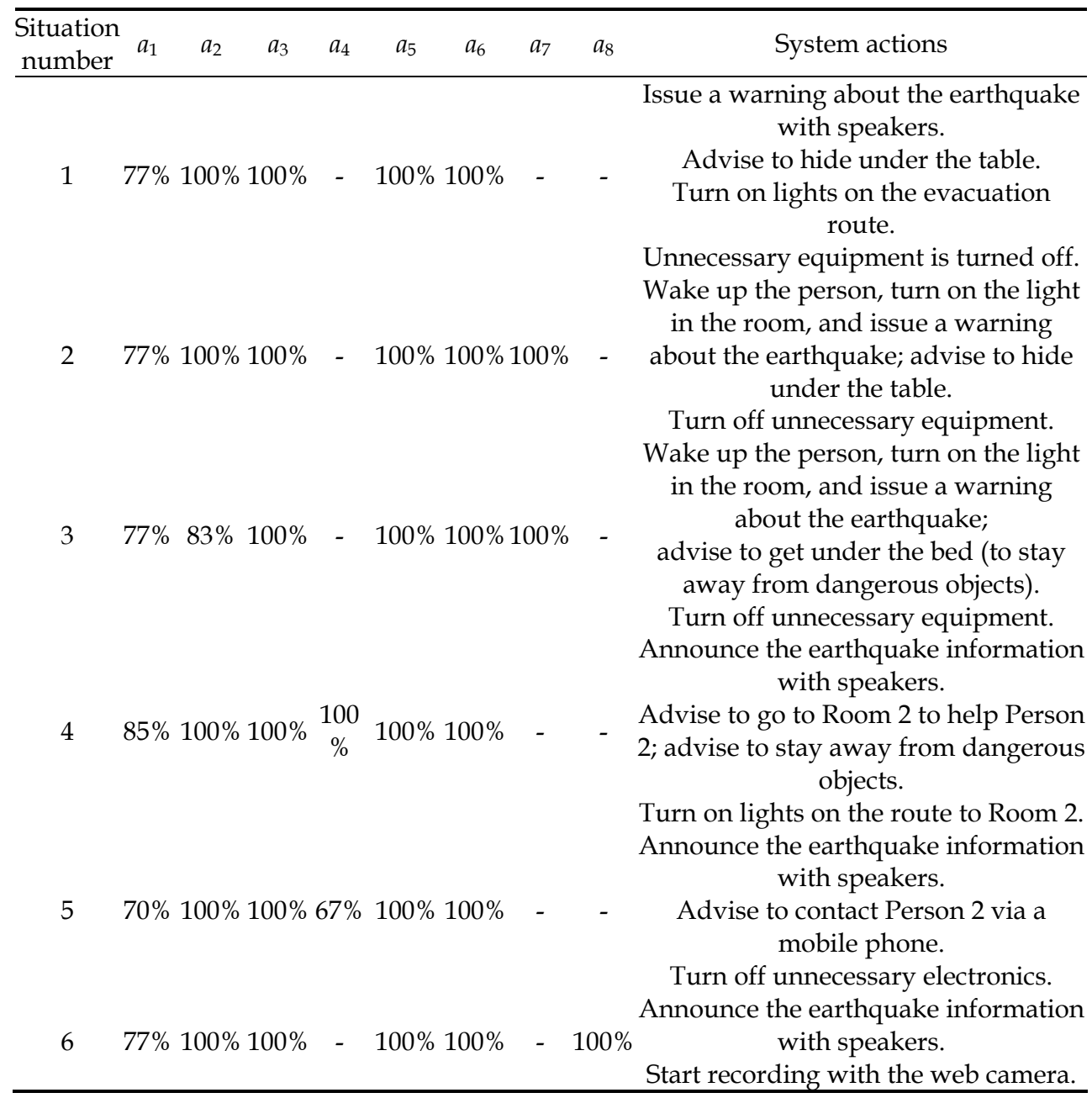

Table 6. Constraint achievement degrees and system actions

To explore these factors, we have conducted experiments for estimating human evacuation rates with external guidance by a prototype of the proposed system (results of one experiment comparing evacuation rates for a house with and without external guidance by the developed prototype were reported elsewhere (Kokawa et al., 2007); Section 5.3 presents a similar experiment, in which the evacuation rates were estimated for a public facility). Since it is usually impractical to test systems with goals analogous to the ones of the developed prototype in real-world settings on a sufficiently (for validation purposes) large scale due to high risks (for both involved people and equipment) associated with the evacuation process, we have developed a simulator capable of reproducing living spaces (e.g. houses, apartments, and the like) and public facilities (e.g. schools, hospitals, cinemas, etc.) with people in there. 
The developed simulator allows for evaluating possible human behavior under external guidance, and it calculates the evacuation rate for different guidance policies emerged from instructions issued by the induced disaster prevention system prototype. The simulator thus operates with the household status database and can dynamically change the simulated evacuation policy.

With the simulator, people are represented as "actors" having 4 parameters: a reaction time, a (running) speed, chances of recovery after a collision, and a recovery time. The reaction time (RT) is the delay from the moment when evacuation instructions are issued until when the actor reacts (e.g. starts moving). This time is randomly assigned, based on a lognormal RT model obtained empirically from data of the real human RT to the prototype guidance (an outline of the corresponding experiment is given in the next paragraph). The running speed is the average moving speed, with which actors would proceed towards an exit (the speed is assigned randomly, based on a Gaussian probability distribution model). Chances of recovery after a collision and the recovery time for an actor are determined by utilizing statistics of evacuation processes reported in the literature (D. Heilbing, 2000).

People normally need time to think and decide upon their actions. Therefore, when evacuation instructions are compiled, a realistic human reaction time should be taken into consideration by the system. Fig. 3 shows results of the experiment conducted to obtain a human reaction time model. The model is to create a random RT generator for the simulator. Two types of subjects have been involved in the experiment: in the figure, "Priming" stands for a group of 30 subjects, who knew about the experiment in advance (the solid line), "No priming" - for $30(15+15)$ subjects, who did not possess knowledge about the planned evacuation (the dashed and dotted lines). It is well known that the variance $\left(\sigma^{2}\right)$ and the average $(\mu)$ of human reaction time may differ significantly, depending on the individual's prior knowledge (R. D. Luce, 1986).

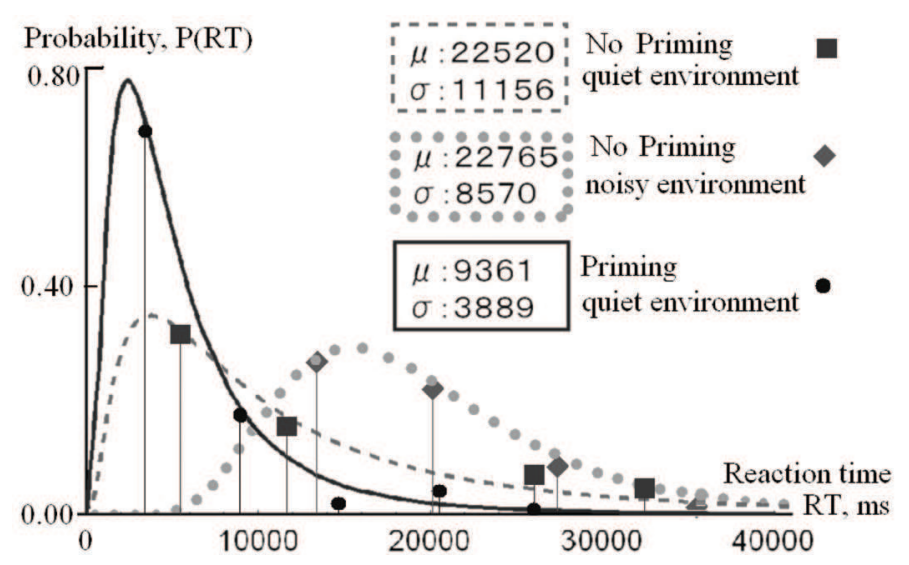

Fig. 3. Human RT patterns in the evacuation process ( $\mu$ and $\sigma$ are the parameters of the lognormal MLE fit to the data; the curves thus show the "best-fit models" obtained from the experimental data)

Two types of situations were explored for the "No priming" group: a quiet, and a comparatively noisy, distracting environments. As can be seen from the figure, the 
"Priming" group and the "No priming, quiet environment" group demonstrated, though expectedly, a significantly faster reaction, on average.

Actors' behavior in the simulation is defined with a few simple rules, which are listed below:

- Actors cannot walk through each other, walls, and furniture.

- Actors start acting (e.g. moving) after a delay determined by the reaction time.

- Actors try to avoid collisions if there is a physical object (e.g. another actor) ahead.

- If an actor collides, it will be delayed or, by chance, even permanently stopped ("killed" in a trample).

- Actors will be delayed when passing in front of an opening door or going on stairs.

- Actors have prior knowledge about the physical environment and the evacuation paths.

\subsection{Experiment 1}

Fig. 4 shows the living space reproduced in the simulation. Room 1 of the space is the room used in the case study described in Section 4. Totally, there are 3 "big" rooms with the corresponding room agents installed. These room agents are also "in charge of" the adjacent spaces, such as corridors, closet, kitchen, etc. A family of three - "father," "mother," and "child" - was modeled in the experiment as follows.

Father: is fully aware of the installed system and its capabilities; in day-time, is usually not at home; is usually "associated" with a quiet environment.

Mother: is aware of the installed system; spends a significant part of her time at home; in day-time, is mainly "associated" with a noisy, distracting environment (e.g. due to housekeeping activities).

Child: does not know about the installed system; needs help when an earthquake occurs.

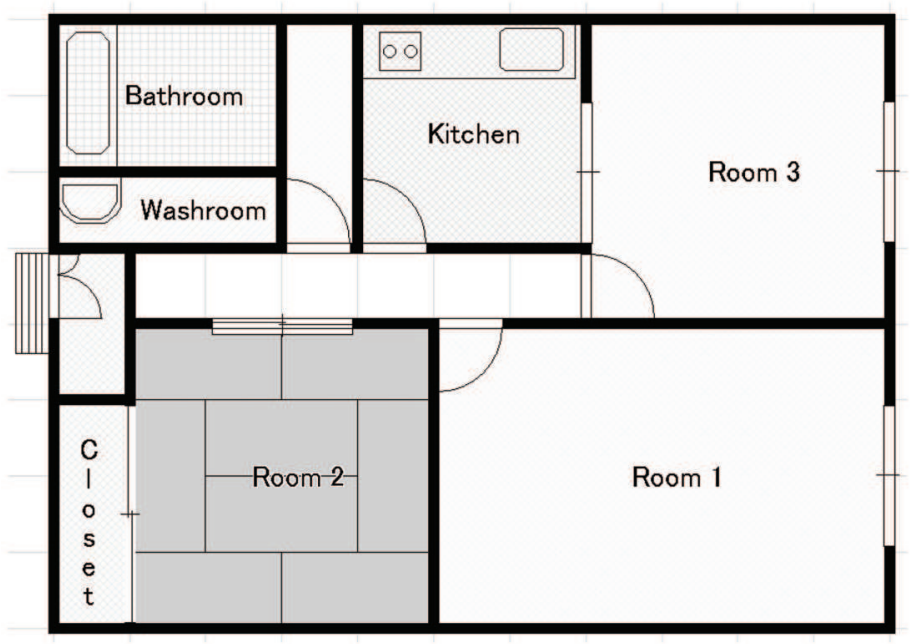

Fig. 4. Living space used in Experiment 1

The flow of the simulated events is as follows. First, an earthquake early warning is initiated at random, and the corresponding data - the seismic intensity and the remaining time - are randomly set. The room agents then decide upon the control of consumer electronics 
specified in the simulator as "installed equipment," and the appropriate evacuation strategies (if any) are implemented. Finally, the damage caused by the earthquake is calculated.

The statuses of the family members are assigned based on the time of the simulated earthquake, as well as on the "most typical/expected" behavior of the members, who are "at home" at the given time. Human responses to the external guidance are modeled, using the detailed information of each room's layout (e.g. see Fig. 2 for the details on Room 1), the relevant RT model, and the current statuses of the inhabitants. The damage $D$ caused by the earthquake is calculated as follows:

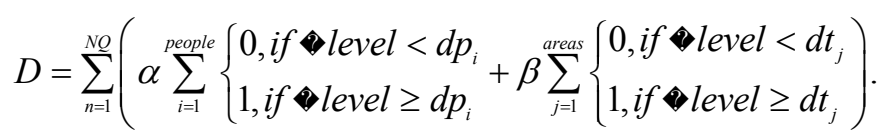

As it may be understood from formula (2), the damage is estimated for $N Q$ simulated earthquakes, and it includes the "human damage" (summation over the people present at the time of the earthquake) and the "living space damage" (summation over the living space areas); level is a simulation parameter proportional to the strength of the simulated earthquake, $d p_{i}$ and $d t_{j}$ are thresholds assigned from empirical data reported in the specialized literature (Heilbing, 2000), and $\alpha$ and $\beta$ are coefficients representing the corresponding damage rates, which are set to values given in post-earthquake reports by the governmental organizations (Government of Japan, 2006).

In this simulation experiment, 3 different disaster-prevention strategies were evaluated: when earthquake information is simply announced with the available electronics (the case of the JMA early warning system - see Section 1), when earthquake information is announced and simple disaster-prevention countermeasures are executed (the case of the JEITA system), and when the full range of the prevention measures available to the system is duly executed (the case of the proposed system). Fig. 5 shows the simulation results. As it

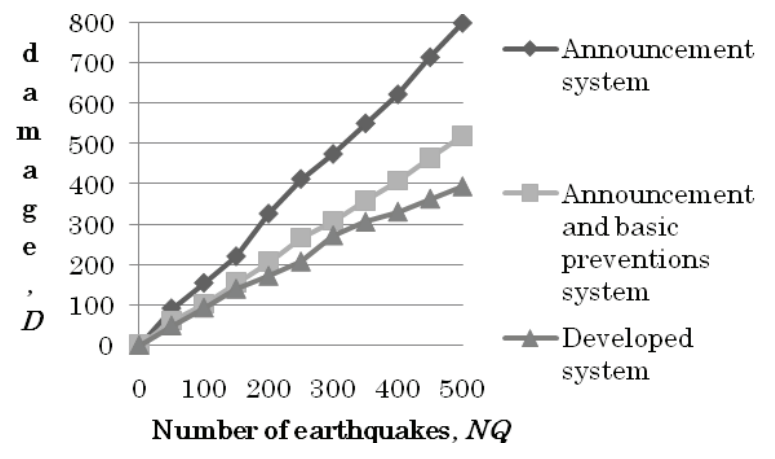

Fig. 5. Experiment 1: Simulation results

can clearly be seen from the graphs, the simple disaster-prevention strategies (lines with filled diamonds and squares), even though appear useful from a common-sense point of view, provide for a significantly lower level of safety (i.e. greater earthquake-induced damage) than the more sophisticated, adaptive strategy implemented with the system 
developed in this study (shown with filled triangles) does. Under other similar conditions, the developed system would help reduce, in a long run and on average, the earthquakeinduced damages by nearly a half, compared to the simplest case of the JMA early warning system.

\subsection{Experiment 2}

We have also conducted a simulation experiment to estimate the possible effect of the guided evacuation of people from a public facility on the evacuation rate. A university's 3story building was modelled with the simulator. This building is normally full of students (the estimated student number is $500 \div 1000$ ) in class-hours. Fig. 6 shows the layout of the building, which has 12 classrooms in its $1^{\text {st }}$ floor and 6 larger lecture halls in each of its higher floors; the floors are connected with two stairs at both sides of the building, where the exits are located. In the simulation model, we did not include the W.Cs and the elevator (denoted $\mathrm{X}$ in the figure).

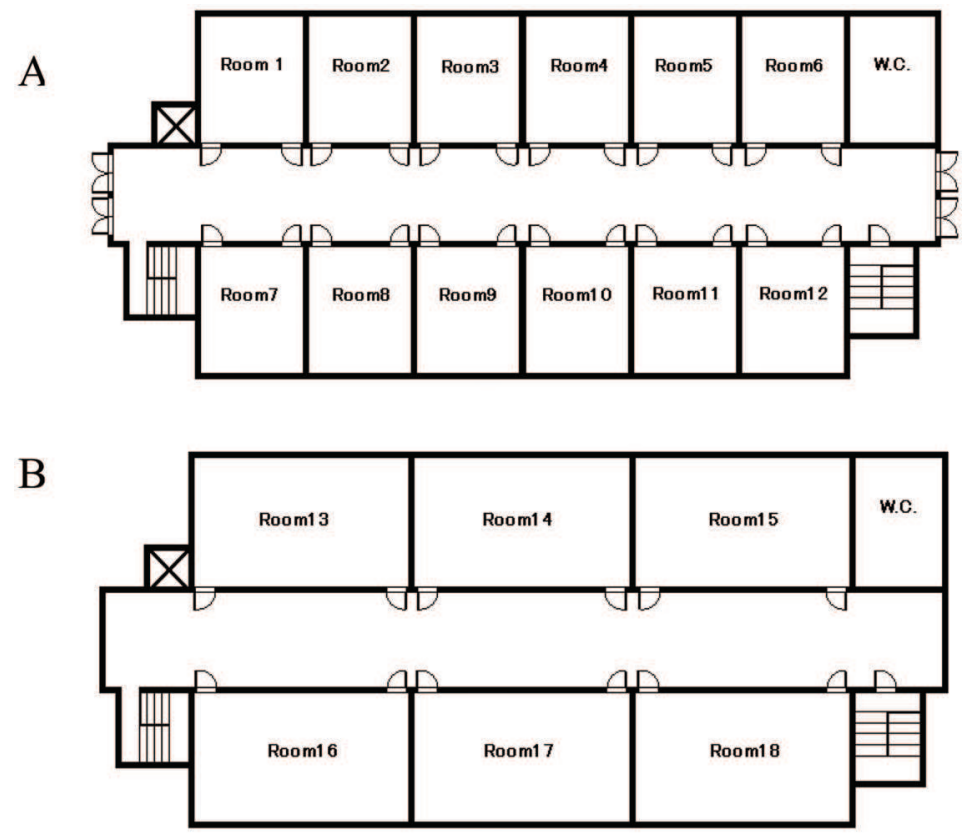

Fig. 6. Layout of the simulated public facility: A - $1^{\text {st }}$ floor, B $-2^{\text {nd }}$ and $3^{\text {rd }}$ floors

In the model used, a teacher was positioned in front of every classroom, and students were randomly distributed over the seats available; the number of students in every class was randomly assigned in the range from 25 to $75 \%$ of the full capacity. It was assumed that when an announcement is made (or an alarm is activated), people inside of the rooms will start moving after a delay, as it is stipulated in Fig. 3 for the "Priming" case. The people will then try to get out of the building, using the relatively narrow doors and stairs. A 3D model of the building with people evacuating is shown in Fig. 7, where the cylinders represent people at a time in the middle of evacuation. 
In the simulation experiment, two types of the evacuation guidance strategies were compared. In the first case, it was assumed that the people, all together, start evacuation when a simple alarm is activated in each room (Sim1 in Fig. 8). The second strategy implies the use of the earthquake-induced disaster prevention system with the room agents installed in the classes. The developed system prototype then decides on the timing of the announcement and its contents (e.g. "Stay in the class," "Quickly move outside! Go to the front stairs," etc.), using its knowledge base and the monitoring agents. In the experiment shown in Fig. 7, the system recommended for the students in rooms 1, 5, 7, 12, 13, 15, 16, and 18 (see Fig. 6) to start evacuation as soon as the earthquake early warning is received; a 5 second delay was recommended for rooms $2,5,8,11,14$, and 17, and a 10 second delay - for rooms 3, 4, 9, and 10. In the given experiment, the total time available for evacuation was varied by the disaster prevention system from 15 to 25 seconds. Results of the evacuation with delays are shown in Fig. 8 as $\operatorname{Sim} 2$.

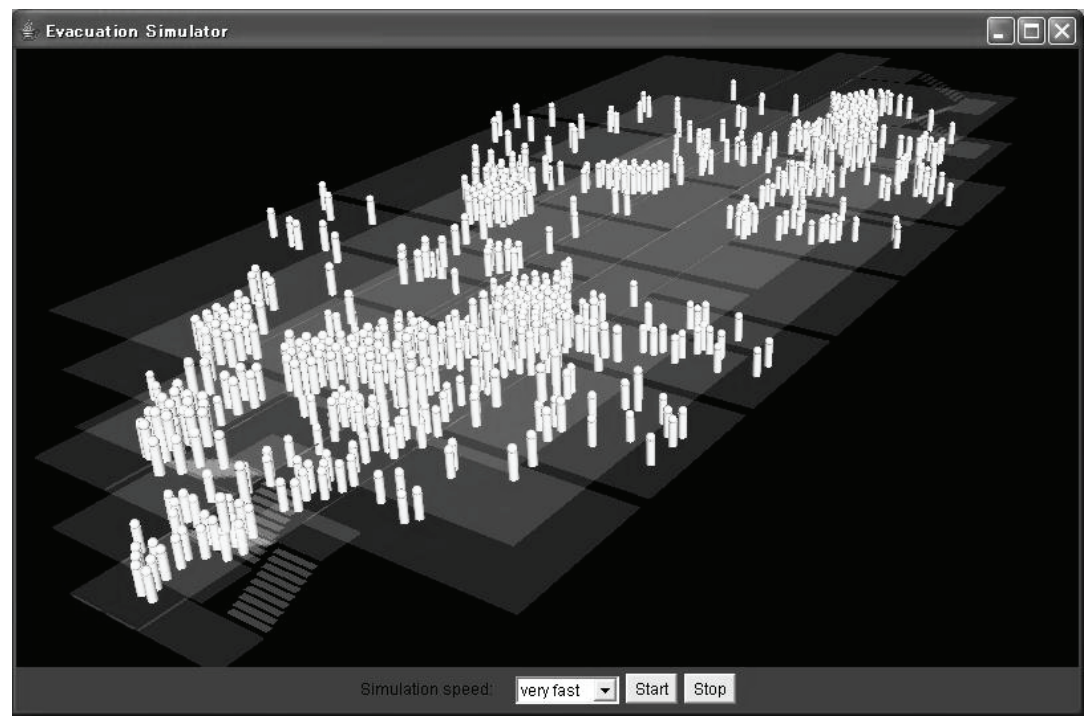

Fig. 7. A screenshot of the simulator during the modelled evacuation process

While the results obtained in the experiment (see Fig. 8, where the graphs are build after averaging over 20 simulations) clearly indicate the advantage of the guided evacuation strategy, it is understood that earthquakes in reality seldom leave us as much as 10 seconds to react. At the same time, however, the purpose of this (second) experiment was not just to test the developed prototype in a different environment and at a larger scale, but rather to show the potential applicability of the proposed system to the case of disasters other than earthquakes - fires, bio- and chemical accidents, etc. The current implementation of the secondary disaster prevention system is quite specialized to deal with the case of earthquakes. It then appears a natural but still unrealized extension of the proposed system concept to generalize it to handle a variety of hazardous situations, possibly using multiple communication networks (in addition to the earthquake early warning network) for obtaining initial data. 


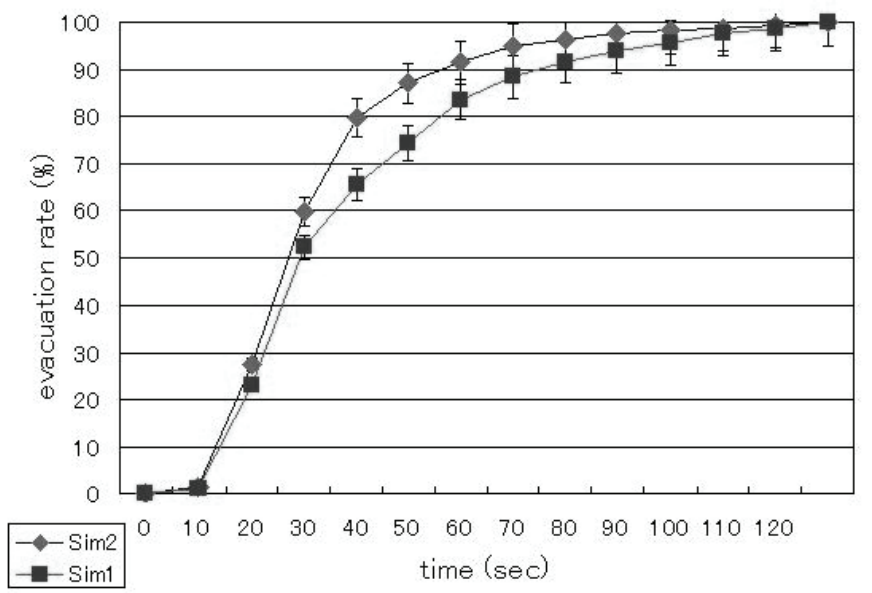

Fig. 8. Results of Experiment 2: the developed system prototype (graph Sim2) provides for a faster evacuation rate than in the case when a simple alarm system, which is usually used at public facilities such as university buildings, is activated (graph Sim1)

\section{Related work}

Most of the relevant studies reported in the literature deal with earthquake early warning systems to merely deliver earthquake-related information to the inhabitants in an effective way. As a typical example, the Real-time Earthquake Information Consortium system was developed to convey earthquake-related announcements to every home in a particular area using IP phones (REIC, 2004). There also were, however, reports in the past few years about systems that have goals and capabilities similar to the ones pursued in the presented study. The system proposed by JEITA is an automatic consumer electronics control system (JEITA, 2005). A somewhat analogous system was developed by Seismic Warning Systems Incorporated, using an earthquake early warning network deployed in the West Coast of the USA (SWS, 2004). Another relevant system was created in Taiwan (Wu et al., 2004). All these systems can control simple electronic devices for the earthquake-induced disaster prevention, utilizing the data obtained from the corresponding early warning systems, e.g. they can shut off gas, issue warnings, open door locks, and so on. The systems have, however, to have countermeasures defined for every possible scenario in advance and, hence, if the environment changes, the recommended actions may become ineffective or even dangerous. Besides, the consistency of the systems' knowledge bases appears hard to maintain due to the changing surroundings.

A wide area of research, which is closely related to our study, is the creation of global and local telecommunication infrastructures (networks) that could be used by various disasterprevention systems. Although not explored in detail in our experiments, it may be natural to expect that the robustness and reliability of the corresponding data- and informationnetworks will, to a large extent, determine the efficiency of automated disaster-prevention systems. The agent-based design proposed in our study can utilize, in its agent-to-agentcommunication part, the best solutions reported in the literature (Harayama \& Inoue, 2006; Lin et al., 2002). 


\section{Concluding remarks}

In the presented study, an intelligent adaptive system to control consumer electronics and guide the evacuation process based on the earthquake early warning has been proposed. The system has an agent-based architecture, and it dynamically implements optimized strategies for the prevention of earthquake-induced disasters by solving an achievementweighted constraint satisfaction problem. The system's sensor-based latent interface allows for adjusting disaster prevention control policies, depending on human behavior in (pre-) earthquake conditions. The system is thus able to adapt to dynamic environments, as its room agents monitor the populated space and update the system's knowledge- and databases.

A system prototype has been created and used in a case study and tests conducted with a simulator, which has also been developed in this research. Experimental results obtained demonstrated that the proposed design solutions provide for a significantly higher level of safety for people in hazardous situations, when compared with the existing disasterprevention systems.

In future work, we plan to increase the flexibility of the system by diversifying control and evacuation strategies potentially available, to connect the system agents to a consumer electronics network, and to develop a new version of the system prototype capable of operation in realistic earthquake conditions. An augmentation of the simulator functionality to provide for dealing with more environmental parameters and to diversify the possible (simulated) interactions among the actors is also planned. A more challenging task remains to develop a secure, efficient and effective but inexpensive technology to monitor human behavior and update the dynamic status database.

\section{References}

S. Bistarelli, P. Codognet, F. Rossi (1999), Abstracting Soft Constraints: Framework, properties, examples, Artificial Intelligence, Vol.139, 1999, pp. 175-211

K. Doi, (2002). Earthquake early warning system in Japan, In: Early Warning System for Natural Disaster Reduction, Jochen Zschau, (Ed.), Springer, Berlin

Government of Japan, (2006) Earthquake occurred in Japan, Disaster Prevention Information Page. Abstract of earthquake countermeasures in Japan, Available from: http://www.bousai.go.jp/jishin/chubou/taisaku_gaiyou/pdf/hassei-jishin.pdf

(last accessed on May 04, 2008) (In Japanese)

H. Harayama, M. Inoue (2006). Study on home network for realization of real-time disasters prevention system, Information Processing Society of Japan, Vol.2006, No.54, 2006, pp. 39-42, ISSN: 0919-6072 (In Japanese)

D. Heilbing (2000). Simulating Dynamical Features of Escape Panic, Nature, Vol. 407, Sep 2000, pp. $487-490$

JEITA (2005). IT automatic disaster prevention system, Second Press Release, Japan Electronics and Information Technology Industries Association (JEITA), Japan, 2005.12.7 Available from: http://home.jeita.or.jp/spp/index.html (last accessed on May 04, 2008) (In Japanese)

A. N. Kueppers (2002). Early Warning System for Natural Disaster Reduction, Springer, Berlin 
M. Kikuchi (2004). The development of a software system to utilize the earthquake real-time information, Ministry of Education, Culture, Sports, Science and Technology Research Report, pp. 410-425, Tokyo ,Japan, (In Japanese)

T. Kokawa, H. Ogawa (2004). A decision-making support system in consideration of individual preferences, The Institute of Electronics, Information and Communication Engineers(IEICE), Technical Report, Vol. 104, No. 133, Tokyo, Japan, 2004, pp. 1-6 (In Japanese)

T. Kokawa, Y. Takeuchi, R. Sakamoto, H. Ogawa, V. V. Kryssanov (2007). An Agent-Based System for the Prevention of Earthquake-Induced Disasters, Proceedings of IEEE International Conference on Tools with Artificial Intelligence, Oct. 2007, pp. 55-62, ISBN: 978-0-7695-3015-4

Y. Lin, H.A Latchman, M. Lee, and S. Katar (2002). “A power line Communication Network Infrastructure for the Smart Home", IEEE Wireless Communications, Vol.9, Issue.6, 2002, pp. 104-111, ISSN: 1536-1284

R.D. Luce (1986). Response times: their role in inferring elementary mental organization, Oxford University Press, New York, USA

X. Luo, J. H. Lee, H. Leung, N. R. Jenningsa (2002), Prioritised fuzzy constraint satisfaction problems: axioms, instantiation and validation, Fuzzy Sets and Systems, Vol. 136, No. 2, 2002, pp. 151-188

REIC (2004) Research and Development of Automatic Disaster Prevention System towards Domestic Controlled Network (IP Phone), Real-time Earthquake information Consortium (REIC) http:/ / www.real-time.jp/research/lp/lp-04b.html

T. Schiex, H. Fargier, G. Verfaillie (1995), Valued constraint satisfaction problems: Hard and easy problems, In Proc. IJCAI-95, 1995, pp. 631-637

SWS (2004), Corporate Backgrounder, Seismic Warning Systems Inc. (SWS), Corporate Overview, 2004

M. Walliser, S. Branschen (2004). M. Calisti, T. Hempfling, Constraint Satisfaction Techniques for Agent-Based Reasoning, Brinkhauser Verlag, Berlin, 2004

Y. M. Wu, T. L. Teng, N. C. Hsiao, T. C. Shin, W. H. K. Lee and Y. B. Tsai (2004). Progress on Earthquake Rapid Reporting and Early Warning Systems in Taiwan, In: Y. T. Chen, G. F. Panza, Z. L. Wu (Ed), Earthquake Hazard, Risk, and Strong Ground Motion, Seismological Press, Berlin, 2004, pp. 463-486

M. Yokoo (2001), Distributed Constraint Satisfaction, Foundations of Cooperation in Multiagent System, Springer-Verlag, New York 


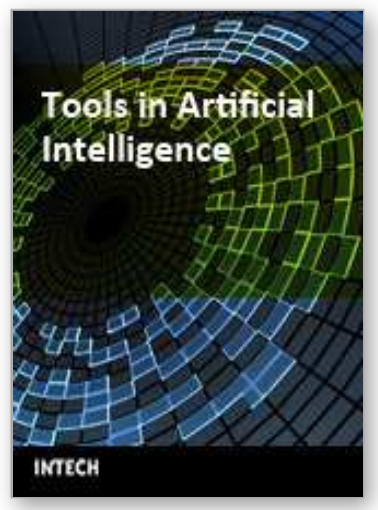

\author{
Tools in Artificial Intelligence \\ Edited by Paula Fritzsche
}

ISBN 978-953-7619-03-9

Hard cover, 488 pages

Publisher InTech

Published online 01, August, 2008

Published in print edition August, 2008

This book offers in 27 chapters a collection of all the technical aspects of specifying, developing, and evaluating the theoretical underpinnings and applied mechanisms of Al tools. Topics covered include neural networks, fuzzy controls, decision trees, rule-based systems, data mining, genetic algorithm and agent systems, among many others. The goal of this book is to show some potential applications and give a partial picture of the current state-of-the-art of Al. Also, it is useful to inspire some future research ideas by identifying potential research directions. It is dedicated to students, researchers and practitioners in this area or in related fields.

\title{
How to reference
}

In order to correctly reference this scholarly work, feel free to copy and paste the following:

Yoshiya Takeuchi, Takashi Kokawa, Ryota Sakamoto, Hitoshi Ogawa and Victor V. Kryssanov (2008). An Agent-Based System to Minimize Earthquake-Induced Damages, Tools in Artificial Intelligence, Paula Fritzsche (Ed.), ISBN: 978-953-7619-03-9, InTech, Available from:

http://www.intechopen.com/books/tools_in_artificial_intelligence/an_agent-

based_system_to_minimize_earthquake-induced_damages

\section{INTECH}

open science | open minds

\section{InTech Europe}

University Campus STeP Ri

Slavka Krautzeka 83/A

51000 Rijeka, Croatia

Phone: +385 (51) 770447

Fax: +385 (51) 686166

www.intechopen.com

\section{InTech China}

Unit 405, Office Block, Hotel Equatorial Shanghai

No.65, Yan An Road (West), Shanghai, 200040, China

中国上海市延安西路65号上海国际贵都大饭店办公楼 405 单元

Phone: +86-21-62489820

Fax: $+86-21-62489821$ 
(C) 2008 The Author(s). Licensee IntechOpen. This chapter is distributed under the terms of the Creative Commons Attribution-NonCommercialShareAlike-3.0 License, which permits use, distribution and reproduction for non-commercial purposes, provided the original is properly cited and derivative works building on this content are distributed under the same license. 